\title{
Technical Efficiency and Environmental Impact of Seabream and Seabass Farms
}

Rasmus Nielsen* is an associate professor, Department of Food and Resource Economics, Faculty of Science, Copenhagen University, Rolighedsvej 25, 1958 Frederiksberg C, Denmark (email: Rasmus Nielsen: rn@ifro.ku.dk). ORCiD (0000-0001-7357-6965)

Isaac Ankamah-Yeboah is a lecturer, Department of Agricultural Economics and Agribusiness, College of Basic and Applied Sciences, University of Ghana, Legon-Accra, Ghana (email: iankamahyeboah@ug.edu.gh).

Ignacio Llorente is an associate professor, Departamento de Administración de Empresas, Facultad de Ciencias Económicas y Empresariales, Universidad de Cantabria, Cantabria, Spain (email: 1lorentei@unican.es).

\section{Abstract:}

Sea cage farming of seabream and seabass is the most important form of aquaculture production in the Mediterranean Sea. Despite the continuous global growth in aquaculture production and demand, the economic performance of seabream and seabass companies has not followed the same trend. In recent years, companies have faced successive periods of market instability, with high volatility in supply and market prices that has strongly affected their operational margins. Despite the regional importance of this industry, only a handful of studies have examined the economic performance of these farms. In this paper, we investigate the technical efficiency and scale effects of Mediterranean aquaculture farms. Furthermore, environmental impact in terms of nutrient emissions from the farms is examined and discussed. Technical efficiency effects are analysed using Data Envelopment Analysis (DEA), and the bootstrap procedure is used for bias correction. The results show that the mean technical efficiency could be improved by between $16 \%$ and $34 \%$, and scale efficiency suggests that farms could improve their efficiency by operating at an optimal scale. Compared to measurements in previous studies, the environmental variables show that the emission of nutrients from the farms per kilo of fish produced has not changed over the past twenty years. Finally, policy implications suggest that more attention towards improving technical efficiency may help improve the robustness of the sector and that environmental regulation might be needed in order to improve the environmental performance of farms. 


\section{Introduction}

Intensive production of fish in sea cages is a relatively new industry, which started in the 1970s with salmon production in Norway (Asche 2008). At the beginning of the 1990s, industrial production of gilthead seabream (Sparus aurata) and European seabass (Dicentrarchus labrax) started in different countries around the Mediterranean Sea (Llorente and Luna, 2014). During the 1990s, both industries experienced rapid growth in production volume. The salmon industry faced some turbulent times during the 1990s (Asche and Bjørndal 2011) caused by falling prices due to the increased supply. Nevertheless, the salmon industry managed to stay profitable through continuous productivity development and increasing demand, even though productivity growth levelled off towards the end of the 2000s (Asche, Guttormsen and Nielsen 2013; Roll, 2019: Rocha-Aponte and Tveteras, 2020). Similarly, the seabream and seabass industry faced several setbacks during the 2000 s due to falling prices as a consequence of the rapid growth in supply (Llorente et al. 2020). However, the seabass and seabream industry has not been able to expand market demand to the same extent as the salmon industry (Asche et al., 2011). This has led to periods of market instability, with high volatility in supply and market prices that has strongly affected seabream and seabass companies' operational margins (Llorente et al. 2020).

When studying technical efficiency as a means to improve productivity in aquaculture, the focus has been on the farm level (Sharma and Leung 2003; Iliyasu et al. 2014), as this is the key element in a successful aquaculture industry. Technical efficiency can be seen as a performance measure. Thus, technically efficient farms are able to produce more outputs with a given set of inputs than less efficient farms. When industries experience rapid development, innovation and growth, there can be high variation among farmers in terms of the input used and output produced, leading to inefficient use of production inputs. This inefficiency can lead to negative environmental impacts if overuse of some inputs has environmentally damaging effects (Asche, Roll and Tveterås 2009). Technical 
inefficiency can therefore be of interest for environmental regulators, as shown in the Norwegian salmon aquaculture industry (Asche, Roll and Tveterås 2009).

Despite evidence for how important technical efficiency is for successful aquaculture industry development (Karagiannis et al., 2000a; Asche et al., 2009; Asche and Roll, 2013; Roll, 2019: RochaAponte and Tveteras, 2020) as a means to increase productivity growth (Asche et al., 2009; Asche and Roll, 2013), studies addressing this issue within seabream and seabass farming are scarce. The production and market data for seabream and seabass have shown several episodes of increasing production and falling market prices that reduce company margins (Llorente et al. 2020). Since 2017, the industry has experienced a new period of increasing supply and price drops, which has created uncertainty about the possible negative impact on the economic performance of the industry.

Within the seabream and seabass industry, only a few studies on technical efficiency, productivity and profitability are available. Furthermore, they all have a country-level scope, and some date back more than twenty years. One of the main reasons is that seabass and seabream production has taken place in many different countries. Thus, there has not been a common system for data collection (as in Norway for salmon production), which has been a limitation when conducting research to provide policy advice for the sector. The studies conducted have centred on Greece and analysed technical efficiency and productivity at the farm and company levels (Karagiannis et al. 2000a; 2000b; 2002 and Pantzios et al. 2011). The findings revealed that larger farm size and specialization on one of the two species positively affects technical efficiency and that feed and fingerling inputs showed the largest fluctuation of marginal productivity among the farms. Pantzios et al. (2011) concluded that there was considerable technical inefficiency, and the contribution from technical efficiency to the overall productivity growth was almost zero when examining a sample of Greek farms from 19951999. Even though Turkey is the largest producer country today, studies focused there only look at economic performance (Kocak and Tatlidil 2004) and energy efficiency (Bozoglu and Ceyhan 2009) and give a general overview of the industry's functioning (Rad and Köksal 2000; Rad 2007. Italian 
studies (Di Trapani et al., 2014) look at economic performance of offshore and inshore production, concluded that offshore farming presents an opportunity to increase profitability and suggested that it is more environmentally sustainable because of the location being farther from land. In Spain, Sotorrío (2002) concluded that profitability of marine finfish farming could be explained by efficiency and the ability to learn (learning curve). Llorente and Luna (2012) analysed how biological, technical, environmental and economic factors affected profitability, showing that technical and biological aspects may lose importance as production processes are standardized, while the environmental and economic aspects increase in relevance. Finally, Llorente et al. (2020) analysed the economic performance of EU seabass and seabream companies from 2008-2016, concluding that profitability has improved in recent years and that larger companies are more profitable. During this period, the industry underwent a process of concentration and consolidation to overcome efficiency and profitability issues. However, on average, economic performance seems to be still rather poor. Given the negative effects of increased supply on the average market price, this highlights the need to improve production efficiency to enhance productivity and operating margins.

The analyses performed within these studies focused on specific countries, making it difficult to draw conclusions for the sector because the results between countries cannot be compared due to the use of different methodologies, sources of data, and sample sizes. Furthermore, environmental variables were not integrated into any of the previous analyses on economic performance. The purpose of this study is to investigate the technical and scale efficiencies in Mediterranean aquaculture farms and the technical efficiency relationships with environmental variables in terms of nutrient emissions. For estimating technical efficiency, Data Envelopment Analysis (DEA) has been applied using the bootstrap procedure for bias correction of the technical efficiency scores from the basic model. Furthermore, Spearman's correlation has been used to estimate the correlations between the efficiency scores obtained from the DEA model and environmental variables reported from the farms. This paper represents progress beyond the state of the art, being the first study to analyse the technical 
106

107

108

109

Figure 1. Global aquaculture production of seabream and seabass (tonnes) and average price per kilo (USD) 1990-2018

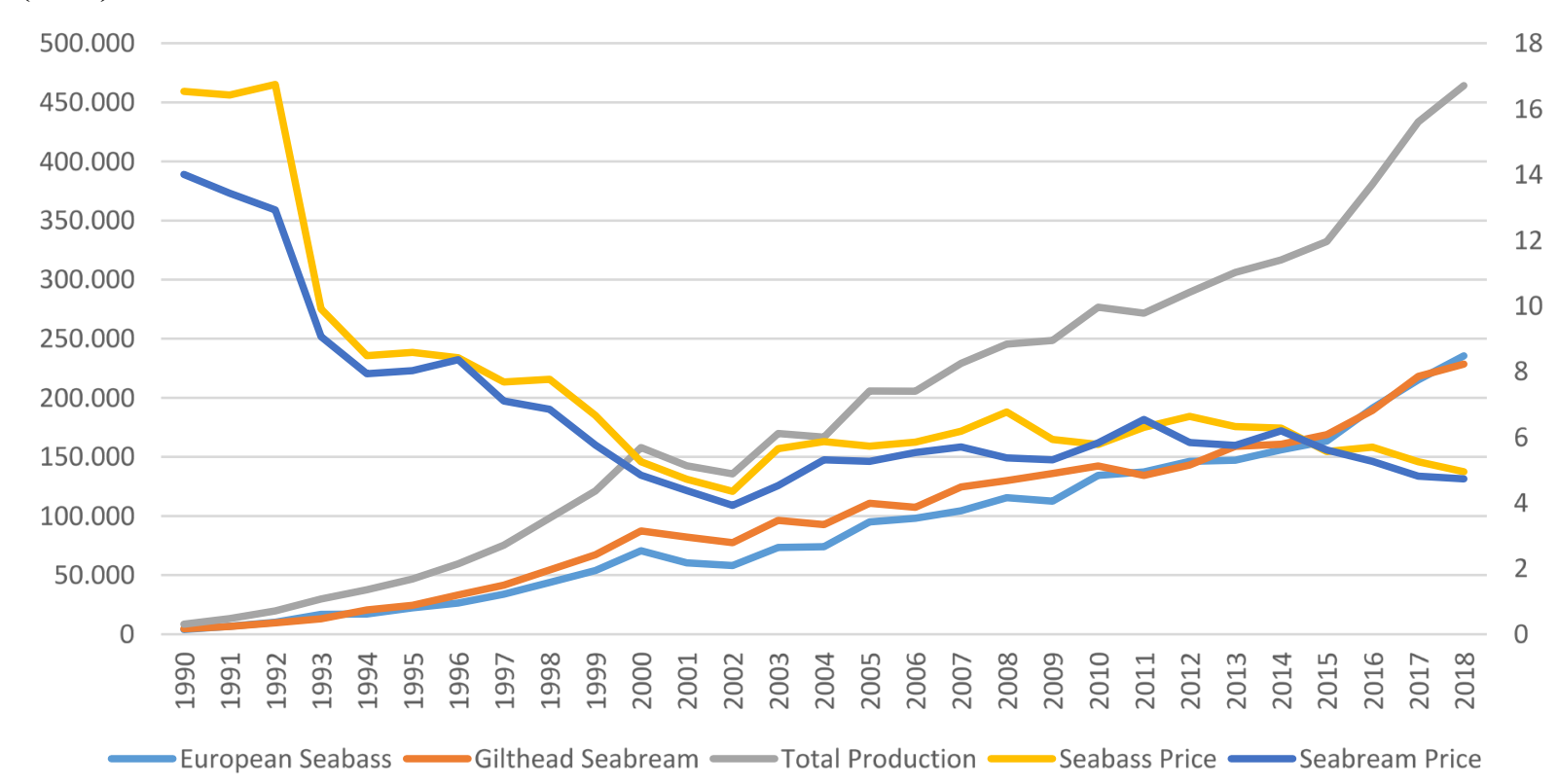

efficiency of seabream and seabass farms in multiple countries that also considers environmental effects.

The study is structured as follows. After this introduction, an overview of the seabream and seabass industry is provided. Then, the methods and materials used are outlined, followed by a presentation and discussion of the results. Finally, the paper is concluded.

\section{Seabream and seabass industry overview}

According to the FAO (FAO, 2020), the total aquaculture production of European seabass and gilthead seabream increased from just under 8 thousand tonnes in 1990 to 158 thousand tonnes in 2000 and up to an impressive 464 thousand tonnes in 2018, valued at 2,247 million dollars. Over the same period, nominal prices decreased from over 16 dollars per kilo in 1990 to 4 dollars per kilo in 2002, which initiated a deep crisis within the sector. Since prices reached an all-time low in 2002, they have been relatively stable, ranging between 5 and 6 dollars per kilo. However, they have shown a decreasing trend since 2011 , reaching a price of 4.73 and 4.95 dollars per kilo for seabream and seabass, respectively, in 2018.

Source: FishStatJ - Software for Fishery and Aquaculture Statistical Time Series (FAO). 
In $2018,95 \%$ of seabream and seabass aquaculture production took place in the Mediterranean Sea. Leading production countries are Turkey and Greece, producing $42 \%$ and $22 \%$ of the total volume, respectively. The five countries with the largest seabass and seabream production (Turkey, Greece, Egypt, Spain, and Tunisia) produced more than $88 \%$ of the total volume in 2018. Turkey, Egypt and Tunisia have considerably increased their production volume since 2008, whereas Greece, Spain and Italy have increased production since 2014, but at a lower rate. Croatia is a new producer of seabass and seabream in this area, producing just over 11,000 tonnes (FAO, 2020).

The production figures show a growing industry that since the crisis in the 2000s has exhibited growth in production volume, especially from 2016 to 2018. The latest data show how the increase in production during 2015 to 2018 has been accompanied by a new reduction in average prices. A greater market share of countries where the product has a lower average value, such as Egypt or Tunisia, may partly explain the fall in the average prices. At present, the increase in production in countries such as Egypt or Tunisia does not seem to have a major impact on the main European markets and trade relations among the rest of the producers, given that most of the fish produced are consumed locally (Cidad et al. 2019).

Before 2012, Greece was the leading producer; however, Turkey has since taken over this role (FAO, 2020). Thus, EU countries are no longer leading the industry. France, Italy and Spain have seen their production stagnate compared to that of countries outside the EU, where the industry is expanding fast. Nevertheless, the EU countries produce a higher-value product, which generates half of the total production value.

The cost structure in the seabream and seabass industry corresponds to that of fish farming in intensive production systems, in which the main cost components are feed (46\%) and fingerlings (14\%) (see Figure 2). Other operational costs make up 19\%, whereas labour costs in the intensive systems are of less importance but still make up 13\% of the overall cost (STECF 2018). 


\section{Figure 2. Cost distribution in seabass and seabream production in EU}
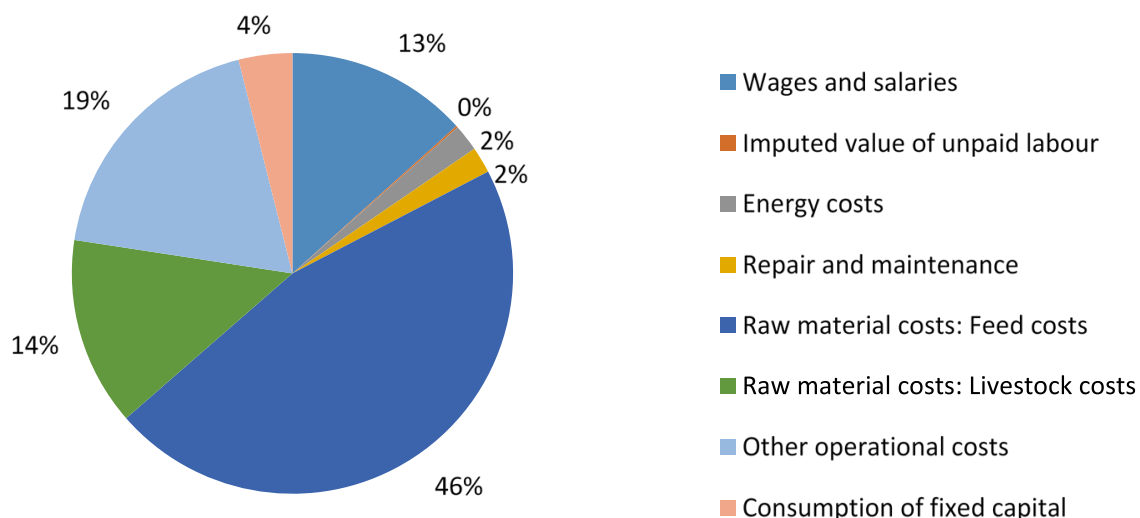

Source: STECF (2018).

\section{Methods and materials}

DEA is used to estimate technical efficiency in the seabream and seabass sea cage industry in the Mediterranean Sea. Charnes, Coopers and Rhodes $(1978,1979)$ introduced the DEA technique, and a general introduction to DEA can be found in Cooper et al. (2000) and Coelli et al. (2005). The methodology has been widely applied to aquaculture, where most studies have focused on analysing technical, allocative and cost efficiencies and aimed to optimize aquaculture production at the farm level (Sharma and Leung 2003; Iliyasu et al. 2014; Long et al. 2020).

In DEA, the distance between the best practice production (the estimated frontier), which represents technically efficient farms, and the actual production for an individual farm is estimated. In this study, an input-oriented and an output-oriented model are used. The input or output orientation should be selected according to which factors farmers have the most control over (Banker et al. 1984). Nevertheless, we report results from both input- and output-oriented models. Input-oriented technical efficiency measures the farm's ability to use the smallest possible set of inputs to produce a given output, considering the available technology, whereas technical efficiency in an output-oriented model measures the farm's ability to use a given set of inputs to produce the maximum set of outputs. In general, VRS is the most appropriate choice because constant returns to scale are only appropriate when farms are operating at an optimal scale (Coelli et al. 2005). Factors such as constraints on 
finance or regulation may influence the individual farm's ability to operate at an optimal level. When using an input- or output-oriented DEA model with VRS, pure technical efficiency (TE) is estimated. In the model, discretionary variables are used. Discretionary variables can be varied at the discretion of the individual farm manager, whereas a non-discretionary variable cannot be changed in the short term. The input-oriented VRS DEA model can formally be written as follows (Coelli et al. 2005):

$\operatorname{Min}_{\theta, \lambda} \theta \quad$ st.:

$Y_{f, k} \leq \sum_{n=1}^{F} \lambda_{n} \cdot Y_{n, k}$

$$
k=1, \ldots, \mathrm{K}
$$

$\theta \cdot X_{f, m} \geq \sum_{n=1}^{F} \lambda_{n} X_{n, m}$

$$
m=1, \ldots, \mathrm{M}
$$

$\lambda_{n} \geq 0, \quad \sum_{n=1}^{F} \lambda_{n}=1$

$n=1, \ldots, \mathrm{F}$

The subscript $f(f=1, \ldots, \mathrm{F})$ represents the $f^{\prime}$ th farm, where $\mathrm{F}$ is the total number of farms. $Y_{f, k}$ is the $k^{\prime}$ th $(k=1, \ldots, \mathrm{K})$ output for the $f^{\prime}$ th farm, and $X_{\mathrm{f}, \mathrm{m}}$ is the $m^{\prime}$ th $(m=1, \ldots, \mathrm{M})$ discretionary input for the $f^{\prime}$ th farm. The scalar $\theta$ measures the radial reduction in the discretionary input necessary to make the farm technically efficient and is between 0 and 1 in an input-oriented approach. If $\theta$ equals 1 , the farm is technically efficient. Finally, $\lambda$ is a vector of $\mathrm{F}$ weights, or intensity variables, which identifies the extent to which the different observations are used to construct that part of the piecewise linear frontier approximation that envelops the $f^{\prime}$ th data point.

The restrictions imposed by equations (1.a)-(1.b) ensure that the farm stays within the production possibility set for the sector when reducing the discretionary inputs $X$. The production possibility set is based on the assumption that it is impossible to produce more outputs than the observed ones, or a linear combination of these (equation 1.a), using less than their observed inputs or linear combinations of these (equation 1.b). VRSs are assumed by the inclusion of equation 1.c (an example of an outputoriented model is shown in Appendix 1). 
Scale efficiency (SE) can be measured by estimating both a CRS and a VRS DEA. The technical efficiency measures obtained under a CRS DEA contain both pure technical efficiency and scale efficiency. Scale efficiency can be deduced by dividing the technical efficiency score from the CRS DEA by the score obtained from the VRS DEA.

$$
S E_{f}=T E_{f, c r s} / T E_{f, v r s}
$$

The $f^{\prime}$ th farm is scale efficient if $\mathrm{SE}=1$, where an $\mathrm{SE}<1$ indicates scale inefficiency.

A point of criticism of the DEA methodology is that it implicitly assumes that all distances from an observed point to the frontier reflect inefficiency. This may pose a problem because uncertainty and measurement errors are in most cases invariably present in data. To address this issue, the bootstrap technique, suggested by Simar and Wilson $(1998,1999,2000 \mathrm{a})$, is applied because this method can be used to analyse the sensitivity of nonparametric efficiency scores to sampling variation and thereby address the problem of measurement errors. The bootstrap technique allows for estimating confidence intervals for DEA scores. In this study, the bias-corrected technical efficiency scores in input- and output-oriented DEA models are used (Simar and Wilson 1998). The theoretical foundation for the bootstrap approach can be found in the extensive work by Simar and Wilson $(1998,1999,2000$ a, 2000b).

The bootstrap approach is based on re-sampling with replacement from the original observed DEA efficiency scores. It is assumed that the probability distribution of the observed DEA efficiencies imitates the true, but unknown, distribution of the parent population of DEA efficiencies. Thus, if a sample is drawn with replacement from the observed DEA efficiencies, it will be similar to a sample drawn from the population itself. By repeatedly re-sampling from the observed DEA efficiencies, an empirical sampling distribution for DEA efficiencies can be constructed.

Spearman's correlation is applied to test the correlations of technical efficiency scores with the year of production and the environmental variables (Artusi et al. 2002). 
211 The data set contains information on production volumes and costs of inputs and outputs used in the 212 production for individual years. The selected data cover 26 farms in 9 countries, over the period 2015 213 - 2017 (Croatia, Cyprus, Egypt, France, Greece, Italy, Spain, Tunisia, and Turkey). Data were 214 collected in the context of the Mediterranean Aquaculture Integrated Development (MedAID) ${ }^{1}$ 215 project during 2018. However, for some of the farms, the variables chosen for the analysis were not 216 reported. To overcome this issue, missing responses were replaced with values calculated as the mean 217 values from the obtained valid responses from the total data set and then related to the individual 218 farm's volume of output produced following Lien et al. (2006) and Flaten et al. (2005). In this way, 219 a data set containing all variables used for the following analysis has been produced. To test the 220 sensitivity of the different models, the analysis described in the methods section has been run with 221 different variables and for a limited data set containing 14 farms without any constructed variables 222 and an extended data set containing 29 farms, including three farms with more than one constructed 223 variable.

224 Table 1 presents summary statistics of the data collected. Output is the volume of seabream and 225 seabass produced in tonnes. The input variables are the volume of fingerlings and feed used for 226 production in tonnes, and labour is measured as the number of persons involved in the production.

227 The numbers in brackets are the sample sizes of the data originally reported by the farmers.

228 Table 1: Descriptive data for output and input variables selected for the analysis

\begin{tabular}{lcccc} 
& Average & Minimum & Maximum & Std. deviation \\
\hline Output & & & & \\
Harvest in tonnes (26) & 646 & 25 & 1.984 & 548 \\
\hline Input & & & & \\
Fingerling in tonnes (23) & 19 & 1 & 52 & 14 \\
Feed in tonnes (23) & 1.623 & 55 & 4.852 & 1.297 \\
Labour in persons (18) & 45 & 6 & 76 & 23 \\
\hline
\end{tabular}

Source: MEDAID WP1 data collection

\footnotetext{
${ }^{1}$ MedAID (Mediterranean Aquaculture Integrated Development) is funded by the European Union under Horizon 2020 grant agreement number 727315. The goal of MedAID is to increase the overall competitiveness and sustainability of the Mediterranean marine fish-farming sector, throughout the whole value chain.
} 
231 To explore the environmental impact of the sea cage farms, the farmers were asked to report data on 232 the emissions of nitrogen, phosphorus and organic material originating from production. As there 233 were no measurements of these effects on the farms, the effects were estimated by the farmers using 234 the input of feed as a proxy for emissions. The descriptive statistics of environmental variables are 235 reported in Table 2.

Table 2: Descriptive data for environmental effects from the production

Average per

Environmental variables Average Minimum Maximum Std. deviation kilo of output

\begin{tabular}{lccccc}
\hline Nitrogen (22)* & 85 & 2.8 & 243 & 65 & 0.111 \\
Phosphorus (22)* & 9 & 0.3 & 24 & 6 & 0.011 \\
Organic material (22)* & 678 & 22.0 & 1,941 & 519 & 0.888 \\
\hline
\end{tabular}

237 Source: MEDAID WP1 data collection.

238 *The number in ( ) are the number of farms that have reported this data out of 26 farms.

239 The environmental variables are highly correlated with the input variable feed because the contents 240 of nitrogen and phosphorus within the feed strongly determine the emissions from the farms. Thus, 241 overall feed use also determines the emission of organic material because it is currently not possible 242 to collect or harvest organic material or nutrients in open-sea cage farms. Due to the high correlation, 243 it was not possible to include the environmental variables within the first stage of DEA modelling.

\section{Results and discussion}

245 The estimates of mean technical efficiency from the input- and output-oriented DEA models with or 246 without bias correction are presented in Table 3.

247 The results show that the mean technical efficiency scores from the basic DEA models are 0.83 and 2480.84 for the input- and output-orientated models, respectively. The interpretation of this result is that 249 the average farm could reduce inputs by $17 \%$ without reducing outputs under the input-oriented 250 model, or a farm could increase outputs by $16 \%$ without increasing input use under the output- 
251 oriented model if the average farm were producing in the manner of the best-practice farms in the 252 sample.

Table 3: Mean Technical Efficiency scores estimated in the DEA models

\begin{tabular}{lllll} 
& \multicolumn{2}{l}{ DEA basic models } & \multicolumn{2}{l}{ DEA Bootstrap models } \\
\cline { 2 - 5 } & $\begin{array}{l}\text { Input } \\
\text { oriented }\end{array}$ & $\begin{array}{l}\text { Output } \\
\text { oriented }\end{array}$ & $\begin{array}{l}\text { Input } \\
\text { oriented }\end{array}$ & $\begin{array}{l}\text { Output } \\
\text { oriented }\end{array}$ \\
\hline Mean TE-score & 0.83 & 0.84 & 0.73 & 0.66 \\
No. of farms & 26 & 26 & 26 & 26 \\
Efficient farms & 9 & 9 & 0 & 0 \\
St. deviation & 0.17 & 0.17 & 0.13 & 0.11 \\
Maximum & 1.00 & 1.00 & 0.91 & 0.81 \\
Minimum & 0.49 & 0.51 & 0.46 & 0.44 \\
\hline Lower 95\% CI for Mean & & & 0.63 & 0.54 \\
Upper 95\% CI for Mean & & & 1.01 & 0.88 \\
\hline
\end{tabular}

Because some missing values have been constructed using mean values from the other farms in the sample, following the method of Lien et al. (2006) and Flaten et al. (2005), a sensitivity analysis of the DEA models and technical efficiency scores was performed.

First, a DEA model containing only 14 farms with all variables present in the original data set was estimated using harvest in tonnes as output and feed and fingerlings in tonnes and labour in numbers of people employed as input. The results show that according to the conventional input- and outputoriented model, the technical efficiency was 0.84 and 0.82 , respectively. The scale efficiency for the input-oriented model was estimated to be 0.91 , and that for the output-oriented model was 0.93 (Appendix 2).

Second, a model containing 29 farms was estimated using the full data set with missing values interpolated. The results showed that for both the conventional input- and output-oriented models, the technical efficiency was 0.83 , and the scale efficiency was 0.91 . Bootstrapping the technical efficiency scores from the DEA model with 29 farms resulted in an average technical efficiency score of 0.69 and 0.70 for the input- and output-oriented models, respectively (Appendix 2). 
Thus, from the sensitivity analysis provided here, we can conclude that the model is robust and that the construction of a few variables does not affect the mean technical efficiency estimated within this study. Furthermore, the results from Danish aquaculture (Nielsen 2011, 2012 and Nielsen et al 2014) also confirm that aquaculture production within comparable production systems is quite homogenous, which suggests that the estimated values for a few inputs on a few farms do not have significant effects on the overall results. Finally, Guttormsen (2002) showed that the most important input in the salmon industry was feed and that limited input substitution possibilities existed in the salmon industry, which also suggested limited input variation among seabream and seabass farms.

The results correspond to findings in Karagiannis et al. (2002), where the technical efficiency was estimated to be $83.7 \%$. Technical efficiency in Norwegian sea cage farming was estimated to be 81.5\% using stochastic frontier analysis (Asche and Roll 2013).

A recent study on aquaculture raised the issue of bias correcting technical efficiency estimates (Long et al. 2020) in order to provide confidence intervals and obtain more valid estimates of technical efficiency using DEA. The results of the bias-corrected models for input and output orientation had a mean score of 0.73 and 0.66 , respectively, which are lower than the values for the ordinary DEA model. This is expected due to the construction of the bias-corrected models and is similar to the findings in Long et al. 2020. The results from the bias-corrected models imply that farms could reduce input by $27 \%$ and still produce the same output or keep the input level and produce $34 \%$ more output if they were all able to produce at the level of the best farmers in the sample. These results correspond to findings in Karagiannis et al. 2000a, where the mean technical efficiency of Greek seabass and seabream farms under output- and input-oriented models was estimated to be $78.5 \%$ and $73.6 \%$, respectively, using a stochastic frontier model.

It seems reasonable to expect that farm technical efficiency could be improved by between $16 \%$ and $34 \%$. In contrast to the Norwegian salmon sea cage farming industry, seabream and seabass producers are located all along the Mediterranean coast in different countries applying different rules and 
regulations for the aquaculture industry (Guillen et al. 2019, STECF 2014, STECF 2016). This may affect technical efficiency because knowledge and innovation may not be transferred as easily as in Norway, where only one set of rules apply. Similar effects have been documented for the land-based trout industry producing relatively small volumes in many EU countries (Nielsen et al. 2016). In Norway, the public sector has also supported innovation and development within the industry (Asche and Bjørndal 2011). The support of governments for innovation and development may be different (lower) within the Mediterranean countries because the sector in each country is smaller, and the benefits of new innovations will be transferred to all the producing countries.

In Table 4, the mean scale efficiency (SE) is shown for the four estimated models. The estimated mean scale efficiencies for the basic DEA models with input and output orientation are 0.91 and 0.90 , respectively. For the DEA bootstrap models, the estimated mean scale efficiencies for the input- and output-oriented models are 0.79 and 0.87 , respectively. The results from the basic DEA analysis indicate that farms could either increase their production by $10 \%$ using the same amount of input as used today or reduce the input used by $9 \%$ and still produce the same amount of fish as produced today if they adjusted their scale of operation (size of farms) to the optimal scale.

Table 4: Mean Scale Efficiency estimated in the DEA models

\begin{tabular}{lcccc}
\cline { 2 - 5 } & \multicolumn{2}{c}{ DEA basic models } & \multicolumn{2}{c}{ DEA Bootstrap models } \\
\cline { 2 - 5 } & $\begin{array}{c}\text { Input } \\
\text { oriented }\end{array}$ & $\begin{array}{c}\text { Output } \\
\text { oriented }\end{array}$ & $\begin{array}{c}\text { Input } \\
\text { oriented }\end{array}$ & $\begin{array}{c}\text { Output } \\
\text { oriented }\end{array}$ \\
\hline Mean Scale Efficiency & 0.91 & 0.90 & 0.79 & 0.87 \\
No. of farms & 26 & 26 & 26 & 26 \\
Scale Efficient farms & 6 & 6 & 0 & 0 \\
\hline
\end{tabular}

The analyses of farm economics provided by Karagiannis et al., 2000a and 2002 and Llorente et al 2020 suggest that economics of scale exist within the sea cage farming of seabream and seabass. Furthermore, looking at the development of the sea cage farming sector in Norway, there is evidence that economies of scale (Asche et al. 2013b and Asche et al. 2018) and production by each company have been increasing over time (Asche, Guttormsen and Nielsen 2013). However, it has also been 
Table 5: Spearman's correlation of years and environmental variables

\begin{tabular}{|c|c|c|c|c|c|c|c|c|c|c|c|c|}
\hline \multirow{3}{*}{$\begin{array}{l}\text { Models } \\
\text { Variables }\end{array}$} & \multirow{2}{*}{\multicolumn{3}{|c|}{$\begin{array}{l}\text { DEA Input } \\
\text { p- }\end{array}$}} & \multirow{2}{*}{\multicolumn{3}{|c|}{ DEA Input BIAS }} & \multirow{2}{*}{\multicolumn{3}{|c|}{$\begin{array}{c}\text { DEA Output } \\
\mathrm{p}-\end{array}$}} & \multicolumn{3}{|c|}{ DEA Output BIAS } \\
\hline & & & & & & & & & & & $\mathrm{p}-$ & \\
\hline & $\mathrm{S}$ & val. & rho & $\mathrm{S}$ & val. & rho & $\mathrm{S}$ & val. & rho & $\mathrm{S}$ & val. & rho \\
\hline Year & 4239 & $* 0.02$ & -0.45 & 4121 & $* 0.04$ & -0.41 & 4189 & $* 0.03$ & -0.43 & 3581 & 0.27 & -0.22 \\
\hline $\begin{array}{l}\text { Nitrogen } \\
(22)\end{array}$ & 2616 & 0.61 & 0.11 & 3124 & 0.74 & -0.07 & 2262 & 0.27 & 0.23 & 1537 & $* 0.01$ & 0.47 \\
\hline $\begin{array}{l}\text { Phosphorus } \\
\text { (22) }\end{array}$ & 2589 & 0.58 & 0.11 & 3077 & 0.80 & -0.05 & 2244 & 0.25 & 0.23 & 1524 & $* 0.01$ & 0.48 \\
\hline $\begin{array}{l}\text { Organic } \\
\text { material } \\
(22)\end{array}$ & 2604 & 0.59 & 0.11 & 3108 & 0.76 & -0.06 & 2254 & 0.26 & 0.23 & 1531 & $* 0.01$ & 0.48 \\
\hline
\end{tabular}

shown that there are significant cost savings associated with localization (agglomeration) because farms can benefit from each other in terms of logistics and knowledge transfer (Tveterås 2002).

A study by Tveterås and Heshmati (2002) indicated that two-thirds of the productivity growth in Norwegian salmon aquaculture originated from input providers and improved inputs, while one-third originated from better production practices at the farm level. Another study (Asche, Roll, and Tveteras 2007) compared the Norwegian sectors producing cod and salmon. The important insight from these studies is that it does not matter where in the value chain productivity growth occurs. Productivity growth downstream in the supply chain may be just as important as improved production methods at the farm level because consumers are only interested in the final price of the product, not where the cost reduction happens within the value chain. Furthermore, it is pointed out in Bergesen and Tveterås, 2019 that suppliers of input to aquaculture businesses are highly innovative, while aquaculture companies largely incorporate innovations from these input suppliers and thereby become more productive.

Significance codes: '*’ 0.05

Spearman's correlation has been used to test how the technical efficiency of farms correlates with the time period 2015-2017 and interacts with the environmental variables nitrogen, phosphorus and organic material. Each of the variables is tested individually against the different efficiency scores obtained with the four DEA models. In Table 5, the results from the Spearman correlation tests are shown. 
334 The estimate (rho) between 2016 and 2017 shows a negative sign, meaning that the technical 335 efficiency decreased from 2016 to 2017, which is significant for three out of the four models. There 336 were only two observations in 2015, and thus this year was not compared to 2016 and 2017 due to 337 the lack of observations.

338 For the environmental variables, the results are ambiguous, showing positive estimates for three out 339 of the four models, but with only the DEA output bias-corrected model being statistically significant. 340 A positive rho value indicates that the higher the technical efficiency of the farms is, the higher the 341 emissions of nutrients and organic materials. It must be stressed that the results of the environmental 342 variables should be interpreted with caution given the small sample and that these numbers were 343 reported by farmers based on the feed used in production and can be highly hypothetical. It is a bit 344 surprising that emissions seem to increase with technical efficiency because higher emissions also 345 indicate higher use of feed, which is a cost to the companies. However, an increase in the use of feed 346 can also lead to faster growth of the fish, increasing technical efficiency. If growth in the biomass 347 value exceeds the extra cost spent on feed, it could be an economically attractive strategy to use more 348 feed. The downside is that it also leads to larger emissions from the farms. This feeding strategy was 349 implemented in Danish trout farms before feed quotas were introduced to regulate the emission of 350 nutrients (Nielsen, 2011; Danish environmental protection agency, 2018).

The environmental variables presented in Table 2 show that per kilo of produced seabass and 352 seabream, 0.11 kilos of nitrogen, 0.011 kilos of phosphorus and 0.89 kilos of organic materials are 353 discharged to the sea. The average feed conversion rate (FCR) for the farmers in the sample is 2.3, 354 which means that they use 2.3 kilos of feed to produce 1 kilo of fish. An FCR of 2.3 for seabass was 355 also found in the studies of Bozoglu and Ceyhan 2009 and Gasca-Leyva et al. 2002, which showed 356 FCRs of 2.23 for fish at a size of 400 grams and 2.7 for 700 -gram fish produced in the Mediterranean 357 Sea. 
In the Danish sea cage farming sector producing trout, the emissions are lower. The FCR was on average 1.13 for the years 2016 to 2018 , which corresponds to emissions of 0.04 kilos of nitrogen, 0.004 of phosphorus and 0.10 kilos of organic material per kilo of produced fish (Danish environmental protection agency, 2018). The Danish emissions are approximately one-third of the emissions of nitrogen and phosphorus and nine times lower than the emission of organic material reported by the seabass and seabream farmers in the Mediterranean.

Experience from the Danish aquaculture industry (Danish environmental protection agency, 2018, Nielsen 2011) shows that aquaculture farms may follow two different feeding strategies. The first one is to achieve the fastest growth of the fish by supplying the fish with as much feed as they can consume. This strategy decreases the rotation ${ }^{2}$ time in the cages and brings the fish to market faster. This can save costs because the production facility can be re-stocked faster; however, there will be an increased cost of feed, and the environmental impact is greater because more feed is also wasted. The second strategy is to optimize feed use, which may prolong production time, but on the other hand, better utilization of feed saves costs and has a positive environmental impact. Within the Danish context, the aquaculture farmers shifted from the first strategy to the second strategy when the Danish feed quota system was implemented in the 1990s to protect the water environment (Nielsen et al. 2016).

Studies on sea cage farming (Asche et al. 1999; Tveterås 2002) suggest that farmers have an incentive to internalize negative environmental effects in their production decisions because farm productivity is dependent on good water quality in and around the farms. Thus, if they emit nutrients at levels that are too high, it may affect both short- and medium-term productivity at the farm location. Furthermore, Asche et al. (2009) showed that in the case of Norwegian sea cage farms, increased technical efficiency could be linked to improved environmental effects because better utilization of the feed improved technical efficiency and thereby reduced the environmental impact of the farm.

\footnotetext{
${ }^{2}$ (Guttormsen 2008)
} 
Thus, according to the results for the environmental variables, it can be suggested that farmers in the Mediterranean are not affected by a feedback effect or that the feedback effects are so small that the gains from applying the first strategy (high growth, high use of feed) are economically more attractive. Furthermore, there are no environmental effects exceeding the current environmental regulations in the countries where the fish are produced.

\section{Conclusions}

The purpose of this study was to investigate the technical efficiency and scale effects of Mediterranean Sea cage farms producing seabream and seabass. The technical efficiency effects were analysed for both an input- and an output-oriented DEA model, and the bootstrap procedure was applied for bias correction. Furthermore, the correlations of the technical efficiency scores of the four models with the year of production and the environmental variables reported were tested using Spearman's correlation test.

The results showed that the mean technical efficiency was $0.83-0.84$ in the basic models, and the biascorrected mean technical efficiency was $0.73-0.66$ for the input- and output-oriented models, respectively. The results indicate that, on average, the farmers could reduce their input use by 17 $27 \%$ without reducing the output produced under the input-oriented model, whereas under the outputoriented model, farmers could produce $16-34 \%$ more output without increasing the input used if they were able to produce according to the best farmers in the sample. Farmers could also increase efficiency by approximately $10 \%$ by operating at an optimal scale. Furthermore, the results show that technical efficiency decreased from 2016 to 2017 for the countries represented in the analysis.

For the environmental variables reported, the feed conversion rate (FCR) remained unchanged over the past 20 years when compared to those in previous studies. Furthermore, our study shows that technical efficiency is positively related to the emission of nitrogen (the use of feed). 
405 We recommend that there be a continuous focus on improving technical efficiency because the sector 406 is highly competitive, and producers with lower costs (Egypt and Tunisia outside the EU) are 407 currently increasing their supply. Focusing on improving technical efficiency and the scale of 408 operation could increase profitability and the robustness of the sector to withstand future fluctuations 409 in prices due to the increasing supply.

410 From an environmental regulatory perspective, improved technical efficiency at the farm level can 411 also benefit the environment because feed is used more efficiently and thereby lowers emissions to 412 the surrounding environment. Seeing that feed is the most important input in terms of cost in the 413 seabream and seabass sector, farmers will have an incentive to reduce cost and utilize the feed most 414 effectively. On the other hand, our results indicate that technical efficiency increases with more 415 emissions (feed used), which does not provide farmers with a strong incentive to reduce the use of 416 feed. In this case, public regulation is necessary to provide farmers with an incentive to internalize 417 the environmental externalities into their production decisions, ensuring that future growth in the 418 seabream and seabass sector will become more environmentally sustainable.

\section{Acknowledgements}

420 The authors would like to thank the MedAID (Mediterranean Aquaculture Integrated Development) 421 project, under which this research was conducted. The MedAID project received funding from the 422 European Union's Horizon 2020 Research and Innovation Programme under grant agreement no 423727315 (http://www.medaid-h2020.eu/). 


\section{Literature:}

Artusi, R., Verderio, P., \& Marubini, E. (2002). Bravais-Pearson and Spearman correlation coefficients: meaning, test of hypothesis and confidence interval. The International journal of biological markers, 17(2), $148-151$.

Asche, F. (2008) Farming the Sea. Marine Resource Economics, 23(4), 527-547.

Asche, F., Dahl, R. E., Gordon, D. V., Trollvik T. and Aandal P. (2011) Demand growth for salmon in the European market, Marine Resource Economics, 26(4), 255-265.

Asche, F., Guttormsen, A. G., \& Tveteraas, R. (1999). Environmental problems, productivity and innovations in Norwegian salmon aquaculture. Aquaculture Economics \& Management, 3(1), 19-29.

Asche, F., Roll, K. H., \& Tveteras, R. (2007). Productivity growth in the supply chain - another source of competitiveness for aquaculture. Marine Resource Economics, 22 (3), 329-334.

Asche, F., Roll, K.H. and Tveteras, R. (2009). Future Trends in Aquaculture: Productivity Growth and Increased Production. Economic Inefficiency and Environmental Impact: An Application to Aquaculture Production. Journal of Environmental Economics and Management 58(1):93-105.

Asche, F. and T. Bjørndal (2011) The Economics of Salmon Aquaculture, Wiley-Blackwell: Chichester.

Asche, F. \& Roll, K.H. (2013) Determinants of inefficiency in Norwegian salmon aquaculture. Aquaculture Economics and Management, Pages 300-321.

Asche, F., Guttormsen, A.G. and Nielsen, R. (2013) Future challenges for the maturing Norwegian salmon aquaculture: An analysis of total factor productivity change from 1996 to 2008. Aquaculture 396-399, 43-50.

Asche, F., KH Roll, HN Sandvold, A Sørvig, D Zhang (2013b) Salmon aquaculture: Larger companies and increased production. Aquaculture Economics \& Management 17 (3), 322-339

Asche, F., Sikveland, M., \& Zhang, D. (2018). Profitability in Norwegian salmon farming: The impact of firm size and price variability. Aquaculture Economics \& Management, 21(3), 306-317.

Banker, R.D. (1984) Estimating Most Productive Scale Size Using Data Envelopment Analysis. European Journal of Operational Research. 17, 35-44.

Bergesen, O. and Tveterås, R. (2019). Innovation in seafood value chains: the case of Norway. Aquaculture Economics \& Management, 2019, VOL. 23, NO. 3, 292-320.

Bozoglu, M. and Ceyhan, V. (2009) Energy conversion efficiency of trout and sea bass production in the Black Sea, Turkey. Energy 34,199-204.

Charnes, A., Cooper, W.W., and Rhodes, E. (1978) Measuring the efficiency of decision making units. European Journal of Operational Research, 2, 429-444.

Charnes, A., Cooper, W.W., and Rhodes, E. (1979) Short Communication: Measuring Efficiency of Decision Making Units. European Journal of Operational Research, 3, 339.

Cidad, M., Peral, I., Ramos, S., Basurco, B., López-Francos, A., Muniesa, A., Cavallo, M., Pérez, J., Aguilera, C., Furones, D., Reverté, C., Sanjuan-Vilaplana, A., Brun, E., Jansen, M.D., Tavornpanich, S., Raux, P., Baraibar, E., Cobo, A., Fernández-Polanco, J.M., Llorente, I., Fernández Sánchez, J.L., Luna, M., Luna, L., Odriozola, M., Gulzari, B., Janssen, K., Komen, H. (2018). Assessment of Mediterranean Aquaculture Sustainability. Deliverable 1.2 of the Horizon 2020 project MedAID (GA number 727315), published in the project web site on 21.12.2018: http://www.medaid-h2020.eu/index.php/deliverables/

Coelli, T.J., Rao, D.S.P., O’Donnel. C.J, and Battese. G.E. (2005) An Introduction to Efficiency and Productivity Analysis, Second Edition, Springer, New York. 
Cooper, W.W., Seiford, L.M. and Tone, K (2000) Data Envelopment Analysis. Kluwer Academic Publishers, Boston.

Danish environmental protection agency (2018) Point source pollution report (Punktkilde rapport 2018). Danish Ministry for Environment and Food, December 2019.

Di Trapani, A,M., Filippo Sgroi, Riccardo Testa, Salvatore Tudisca (2014) Economic comparison between offshore and inshore aquaculture production systems of European sea bass in Italy, Aquaculture 434, 334-339.

FAO 2020- Fisheries and Aquaculture Information and Statistics Branch

Flaten, O., Lien, G., Koesling, M., Valle, P. S., \& Ebbesvik, M. (2005). Comparing risk perceptions and risk management in organic and conventional dairy farming: Empirical results from Norway. Livestock Production Science, $95,11-25$.

Gasca-Leyva, E., Carmelo J. León, Juan M. Herna'ndez, J.M. Vergara (2002) Bioeconomic analysis of production location of sea bream (Sparus aurata) cultivation, Aquaculture 213 (2002) 219-232

Guillen, J., Asche, F., Carvalho, N., Polanco, J.M.F., Llorente, I., Nielsen, R., Nielsen, M., Villasante, S. (2019) Aquaculture subsidies in the European Union: Evolution, impact and future potential for growth. Marine Policy. Volume 104, Pages 19-28.

Guttormsen, A. (2002) Input factor substitutability in Salmon aquaculture. Mar. Resour. Econ. 17 (2), 91-102.

Guttormsen, A. (2008) Faustmann in the Sea: Optimal Rotation in Aquaculture. Marine Resource Economics, Volume 23, pp. 401-410.

Iliyasu, A, Zainal Abidin Mohamed, Mohd Mansor Ismail, Amin Mahir Abdullah, Salleh Mohamed Kamarudin \& Hashim Mazuki (2014) A review of production frontier research in aquaculture (2001-2011), Aquaculture Economics \& Management, 18:3, 221-247.

Karagiannis, G., Katranidis, S.D. \& Tzouvelekas, V. (2000a) Measuring technical, allocative and cost efficiencies of seabass and seabream farms in Greece, Aquaculture Economics \& Management, 4:3-4, 191207

Karagiannis, G. \& Katranidis, S.D. (2000b) A Production Function Analysis of Seabass and Seabream Production in Greece. World Aquaculture Society, Vol. 31, No. 3.

Karagiannis, G., Katranidis, S.D. \& Tzouvelekas, V. (2002) Measuring and attributing technical inefficiencies of seabass and seabream production in Greece, Applied Economics Letters, 9:8, 519-522.

Koçak, Ö. \& Tatlıdil, F.F. (2004) Cost analysis in gilthead sea bream (Sparus aurata Linnaeus, 1758) and sea bass (Dicentrarchus labrax Linnaeus, 1758) production in Milas District-Muğla Province, Turkey. Turk. J. Fish. Aquat. Sci., 4 (1) (2004), pp. 33-38.

Lien, G., O. Flaten, O., Jervell, A. M., Ebbesvik, M., \& Koesling, P. S. (2006). Management and risk characteristics of part-time and full-time farmers in Norway. Review of Agriculture Economics, 1, 111-31.

Llorente, I. and Luna, L. (2012) Explanatory model of the profitability of marine fish farming companies. Empirical application to the breeding of seabream (Sparus aurata) and European seabass (Dicentrarchus labrax) in Spain. Economía Agraria y Recursos Nat. Agric. Resour. Econ., 12 (2) (2012), pp. 31-55.

Llorente, I., and Luna, L. (2014). Economic optimisation in seabream (Sparus aurata) aquaculture production using a particle swarm optimisation algorithm. Aquaculture international, 22(6), 1837-1849.

Llorente, I., José Fernández-Polanco, Elisa Baraibar-Dieza María, D. Odriozola, Trond Bjørndal, Frank Asche, Jordi Guillen, Lamprakis Avdelas, Rasmus Nielsen, Maria Cozzolino, Manuel Luna, José L. Fernández-Sánchez, Ladislao Luna, Cristóbal Aguilera, Bernardo Basurco (2020) Assessment of the economic 
performance of the seabream and seabass aquaculture industry in the European Union, Marine Policy, 117, 103876.

Le Kim Long, Le Van Thap, Nguyen Trong Hoai \& Thuy Thi Thanh Pham (2020) Data envelopment analysis for analyzing technical efficiency in aquaculture: The bootstrap methods, Aquaculture Economics \& Management, DOI: $\underline{10.1080 / 13657305.2019 .1710876}$

Nielsen, R., Asche, F. and Nielsen, M. (2016) Restructuring European freshwater aquaculture from family owned to large scale firms - Lessons from Danish aquaculture. Aquaculture Research 47, 3852-3866.

Nielsen, R., Andersen, J.L. and Bogetoft, P. (2014) Dynamic Reallocation of Marketable Nitrogen Emission Permits in Danish Freshwater Aquaculture. Marine Resource Economics 29, 219-239.

Nielsen, R. (2012) Introducing individual transferable quotas on nitrogen in Danish fresh water aquaculture: Production and profitability gains. Ecological Economics 75, 83-90.

Nielsen, R. (2011) Green and Technical Efficient Growth in Danish Fresh Water Aquaculture. Aquaculture Economics and Management 15, 262-277.

Pantzios, C.J., Karagiannis, G. \& Tzouvelekas, V. (2011) Parametric decomposition of the input-oriented Malmquist productivity index: with an application to Greek aquaculture J Prod Anal (2011) 36:21-31.

Rad, F. (2007) Evaluation of the sea bass and sea bream industry in the Mediterranean, with emphasis on Turkey. P. Leung, C.-S. Lee, P.J. O'Bryen (Eds.), Species and System Selection for Sustainable Aquaculture, Blackwell Publishing, Ames, Iowa, USA (2007).

Rad, F. and Köksal, G. (2000) An overview of aquaculture in Turkey: with emphasis on sea bass and sea bream. Aquacult. Econ. Manag., 4 (3-4) (2000), pp. 227-239.

Rocha-Aponte, F. and Tveterås, S. (2019) "On the Drivers of Cost Changes in the Norwegian Salmon Aquaculture Sector: A Decomposition of a Flexible Cost Function from 2001 to 2014." Aquaculture Economics \& Management 23 (3): 276-91.

Roll, K. H. (2019) "Moral Hazard: The Effect of Insurance on Risk and Efficiency." Agricultural Economics (United Kingdom) 50 (3): 367-75.

Sharma, K.R. and R.S. Leung (2003) A Review if Production Frontier Analysis for Aquaculture Management. Aquaculture Economics and Management 7, 15-34.

Simar, L. and Wilson, P.W. (1998) Sensitivity analysis of efficiency scores: how to bootstrap in nonparametric frontier models, Management Science, 44(1), 49-61.

Simar, L. and Wilson, P.W. (1999) Estimating and bootstrapping Malmquist indices, European Journal of Operational Research, 115, 459-471.

Simar, L. and Wilson, P.W. (2000a) A general methodology for Bootstrapping in nonparametric frontier Models, Journal of Applied Statistics, 27(6), 779-802.

Simar, L. and Wilson, P.W. (2000b) Statistical inference in nonparametric frontier models: the state of the art, Journal of Productivity Analysis, 13, 49-78.

Sotorrío, L.L (2002) Economic analysis of finfish mariculture operations in Spain, Aquacult. Econ. Manag., 6 (1-2) (2002), pp. 65-79.

STECF 2014 - Scientific, Technical and Economic Committee for Fisheries (STECF) - The economic performance of the EU aquaculture sector (STECF 14-18). 2014. Publications Office of the European Union, Luxembourg, EUR 27033 EN, JRC 93169, 451 pp. 
STECF 2016 - Scientific, Technical and Economic Committee for Fisheries (STECF) - Economic Report of the EU Aquaculture Sector (EWG-16-12); Publications Office of the European Union, Luxembourg; EUR 28356 EN; doi: $10.2788 / 677322$

STECF 2018 - Scientific, Technical and Economic Committee for Fisheries (STECF) - Economic Report of the EU Aquaculture sector (STECF-18-19). Publications Office of the European Union, Luxembourg, 2018, ISBN 978-92-79-79402-5, doi:10.2760/45076, JRC114801

Tveteras, S. (2002). Norwegian salmon aquaculture and sustainability: the relationship between environmental quality and industry growth. Marine Resource Economics, 17(2), 121-132.

Tveterås, R., \& Heshmati, A. (2002). Patterns of productivity growth in the Norwegian salmon farming industry (SSE/EFI Working Paper Series in Economics and Finance 301). Stockholm: Stockholm School of Economics.

\section{Appendix 1:}

In an output oriented model, technical efficiency $H$ can be estimated for each farm $f$ ' solving the following model:

$\underset{H, \lambda}{\operatorname{Max}} \quad H \quad$ st.:

$H \cdot Y_{f, k} \leq \sum_{n=1}^{F} \lambda_{n} \cdot Y_{n, k}$

$k=1, \ldots, \mathrm{K}$

$X_{f, m} \geq \sum_{n=1}^{F} \lambda_{n} \cdot X_{n, m}$

$m=1, \ldots, \mathrm{M}$

$\lambda_{n} \geq 0, \quad \sum_{n=1}^{F} \lambda_{n}=1$

$\mathrm{n}=1, \ldots, \mathrm{F}$

The subscript $f\left(f=1, \ldots f^{\prime} \ldots, \mathrm{F}\right)$ represents the farms going from 1 to $\mathrm{F}$, where $\mathrm{F}$ is the total number of farms and $f^{\prime}$ is a farm in F. $Y$ is the observed harvest $k(k=1, \ldots, \mathrm{K})$ per year. $X$ is the variables for each of the discretionary inputs $m(\mathrm{~m}=1, \ldots, \mathrm{M})$. The scalar $H$ measures the radial expansion in the discretionary output necessary for making the farm technically efficient, and it is above or equal to 1 in the output-oriented approach. If $H$ equals 1 , the farm is considered to be technically efficient. Finally, $\lambda$ is a vector of $F$ weights, or intensity variables, which identifies the extent to which the different observations are used to construct that part of the piecewise linear frontier approximation that envelops the $f^{\prime}$ data point.

The restrictions imposed by equations (2.a)-(2.b) ensure that the farm stays within the production possibility set for the sector. The production possibility set is based on the assumption that it is impossible to produce more than the observed outputs, or a linear combination of these (equation 2.a and 2.b), using less than the observed inputs or linear combinations of these (equation 2.b). VRS are assumed by inclusion of restriction (2.c). The DEA linear programming model indicates the potential technical efficiency gain for each farm and for the industry as a whole, if all farms were technically efficient, compared to the initial situation.

\section{Appendix 2:}

Mean Technical Efficiency (TE) scores estimated in the basic DEA model with variable returns to scale for 14 and 29 farms and bootstrapping of TE scores for the model with 29 farms 


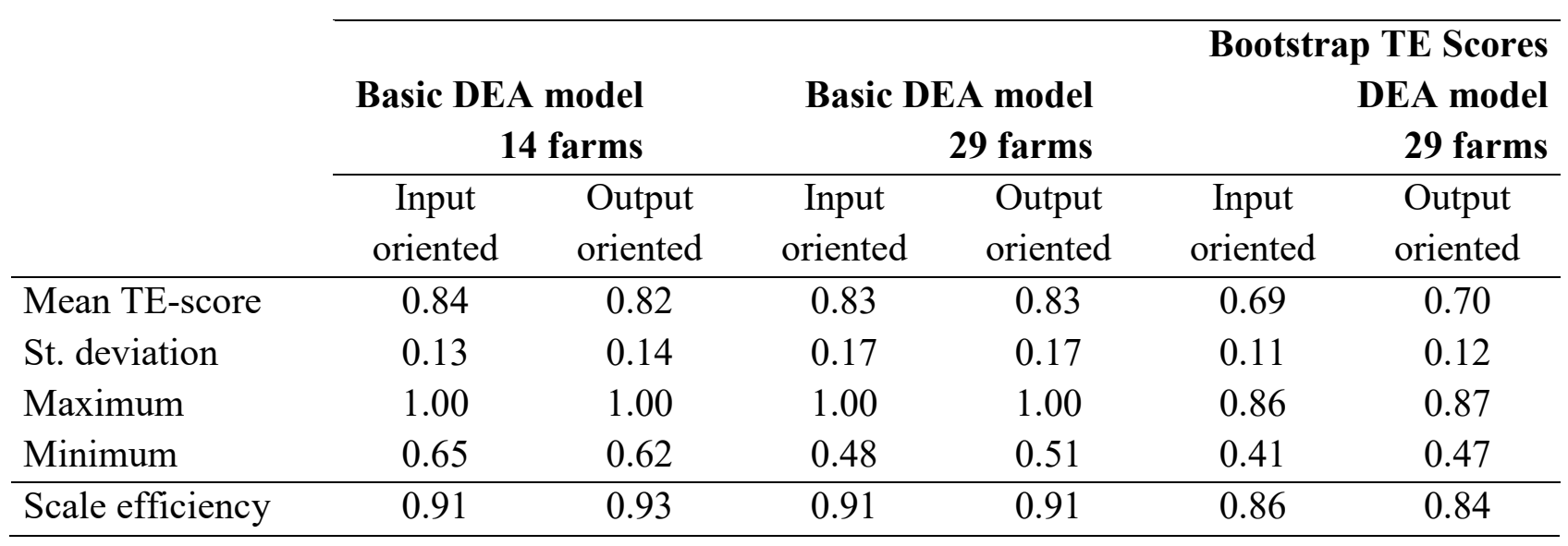

